\title{
NUMERICAL STUDY OF A VENTILATED FACADE PANEL
}

\author{
F. MOOTZ and J.-J. BEZIAN ${ }^{\dagger}$ \\ Centre d'Energétique de l'Ecole des Mines de Paris (CENERG), B.P. 207, 06904 Sophia Antipolis Cédex, \\ France \\ (Communicated by J. Owen Lewis)
}

\begin{abstract}
An energy-saving facade panel for non-residential buildings has been numerically investigated. Structured like a composite Trombe-Michel wall, the panel consists of a glazing, an absorber plate and insulation and contains a dead air space between glazing and absorber, as well as a convection channel between absorber and insulation. The influence of convection channel spacing on both recovery of solar energy during sunshine periods and on heat losses during night hours has been assessed. Two different options have been considered. First, the total panel thickness was maintained, which involves an increase of channel spacing having to be compensated by a corresponding decrease of the insulation thickness. Then, this constraint was removed so that an increase in channel spacing was allowed to entail an equivalent increase of the total panel thickness. The results indicate that large spacing favors energy recovery during sunshine periods for both options and reduces, although only slightly, heat losses during night hours for the second uption. In the case of the first option, however, these losses tend to grow when channel spacing increases. Copyright (C) 1996 Elsevier Science Ltd.
\end{abstract}

\section{INTRODUCTION}

Reducing energy consumption for heating purposes in buildings by means of facades designed to capture incident solar energy has been the target of numerous research work. Some of this work focuses on the improvement of existing solutions (Detung and Bilgen, 1984; Zrikem and Bilgen, 1987) or investigates the usefulness of new designs (Kenna, 1983a,b). Others aim at providing designers with simulation tools to evaluate the thermal performances of different solar systems (Vaxman and Solokov, 1985; Duffin and Knowles, 1985). However, despite the effort involved in conceiving efficient solutions, it is evident that solar components play only a minor role in building construction today. This situation may be partly due to a general disregard for architectural demands, thus disregarding the primary concerns of potential customers. In the present study, an attempt has been made to take these concerns more seriously into consideration while developing a new, lightweight solar air heater particularly suited to office buildings.

Their widespread use in modern office construction makes facade panels an ideal target for promoting energy-saving techniques. Generally chosen in dimension and design to harmonize with the window surface, these panels can, when placed side by side, replace whole building facades.

${ }^{+}$Author to whom correspondence should be addressed.
Substituting these panels with solar panels should be a promising way to reduce energy consumption in office buildings. If the solar panel, furthermore, preserves the design of the original facade panel, then architectural requirements should also be observed. Indeed, since no distinction between both panel types can be made from the outside, the solar panel should, from an architectural point of view, be as appealing as the original that it is meant to substitute. This approach may thus remove one of the obstacles to an increased use of solar air heaters in building construction.

Following this guideline, a commercialized, successful facade panel (Fig. 1a) has been selected and subsequently transformed into a lightweight version of the composite TrombeMichel wall proposed by Zrikem and Bilgen (1987; Fig. 1b).

\section{PROBLEM DESCRIPTION}

Typical solar air heaters provide heat supply during recovery periods, i.e. when incident solar energy raises the temperature of the channel bordering walls above the ambient temperature. As a consequence, air is drawn in through the inlet section, heated up in the convection channel and discharged through the outlet section (Fig. 2a). When, as in our case, the solar panel replaces the building wall itself, additional heat is delivered to the adjacent room by conduction through the insulation. Accordingly, the panel 


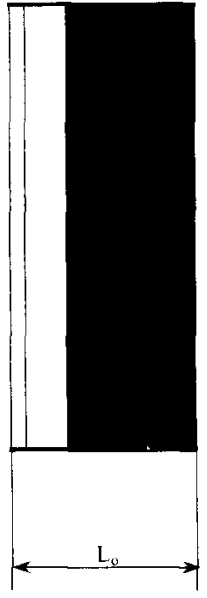

a) b)

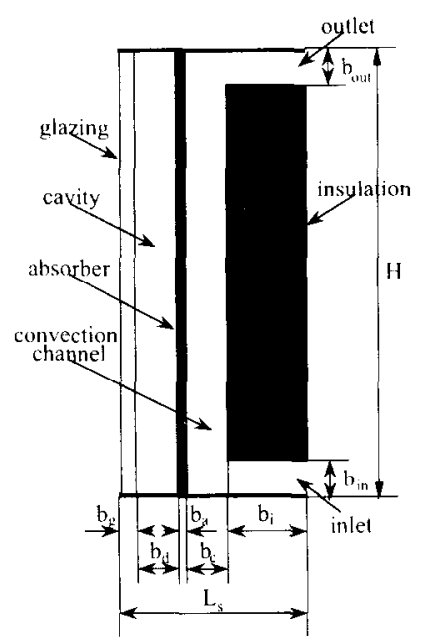

Fig. 1. Sketch of (a) original facade pancl and (b) solar panel.

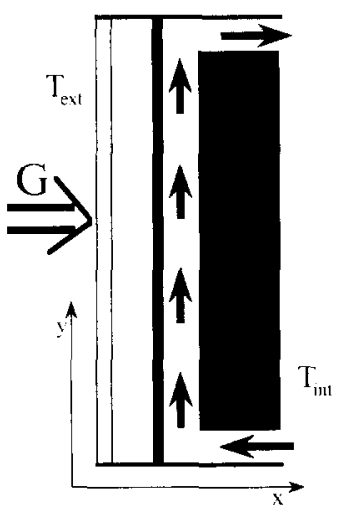

a)

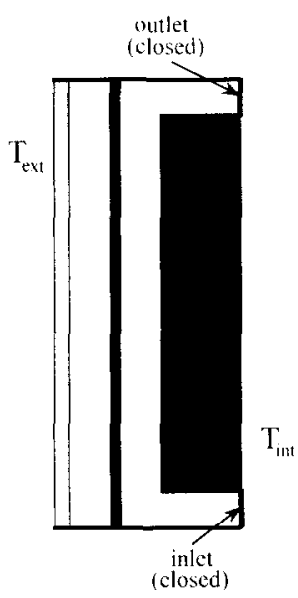

b)
Fig. 2. Operating modes of the panel during (a) recovery periods and (b) non-recovery periods.

efficiency can be defined as follows:

$$
\begin{aligned}
\eta= & \frac{1}{G H}\left(\int_{0}^{b_{\text {in }}} \rho u C T \mathrm{~d} y+\int_{H-b_{\text {out }}}^{H} \rho u C T \mathrm{~d} y\right. \\
& \left.+U_{\text {int }} \int_{b_{\text {in }}}^{H-b_{\text {out }}}\left(T-T_{\text {int }}\right) \mathrm{d} y\right)\left.\right|_{x=L}
\end{aligned}
$$

where the sum of the first two terms encompasses the convective gains, i.e. the enthalpy difference of the air stream between the inlet and outlet section, whereas the last term represents the conductive contributions which correspond to the release of heat on the back of the panel.

The lack of thermal capacitance of the panel due to its lightweight structure implies, however, that heat supply can only be ensured during sunshine periods. As far as night hours and prolonged cloudy periods (non-recovery periods) are concerned, the panel causes heat losses like a normal building. In order to limit the extent of these losses, inlet and outlet sections have to be closed, thus preventing the inflow of cold air due to the reverse air circulation in the convection channel (Fig. 2b). The heat losses caused by the panel during non-recovery periods have been determined as follows:

$$
K=\left.\frac{U_{\text {int }}}{H\left(T_{\text {int }}-T_{\text {ext }}\right)} \int_{0}^{H}\left(T_{\text {int }}-T\right) \mathrm{d} y\right|_{x=L}
$$

where $K$ is the heat-loss coefficient.

Given their frequent occurrence during a typical heating season, non-recovery periods cannot be ignored if the panel performance is to be improved. Considering the importance of this point, an attempt has been made. in this study to optimize the panel with regard to both recovery and non-recovery periods. On account of the architectural constraints, this had to be done in a way which preserved the external panel design. Amongst the few parameters left by this restriction, the variation of the channel spacing $b_{\mathrm{c}}$ was finally chosen, as it was expected to have a significant influence on the panel efficiency. The following two options have been investigated.

\subsection{Option 1: constant panel thickness}

In modern construction, facade panels frequently cover large areas of building facades. If, for some reason, it may only be possible to replace one or a few of the original panels by the equivalent number of solar panels, both panel types must have identical dimensions (otherwise, they could be distinguished from outside). Since this identity ensures that both panels are interchangeable, facades can be covered at will, partly with the solar panel, partly with the original one. Observing this constraint implies that the thickness of the solar panel $L_{\mathrm{s}}$ must equal the thickness of the original panel $L_{\mathrm{o}}$ and be maintained during the optimization study. This can only be achieved if the increase of channel spacing $b_{\mathrm{c}}$ is compensated by an equivalent thinning of another panel part. Given the panel assembly, the only element suitable for this task is the insulation. Consequently, an increase of $b_{c}$ has to be counterbalanced by a corresponding decrease of the insulation thickness $b_{\mathbf{i}}$. 


\subsection{Option 2: variable panel thickness}

Option 2 is based on the assumption that whole building sections are covered with the solar panel alone, which involves the panel dimensions being determined independently. However, in order to facilitate the comparison with option 1, height and width of the original panel are maintained and only the panel thickness can be chosen within a certain range. Thus, $L_{\mathrm{s}}$ can be adjusted to variations in channel spacing which arise during the optimization study, and an increase of $b_{\mathrm{c}}$ is allowed to entail a corresponding increase of $L_{\mathrm{s}}$, whereas the insulation thickness $b_{i}$ can be preserved.

\section{MATHEMATICAL FORMULATION}

The panel is a combination of solid (glazing, absorber plate and insulation) and fluid regions (dead air space and convection channel). The mathematical formulation of this conjugate heat-transfer problem is mainly based on the following assumptions:

(1) Conduction and convection are steady. Although generally not supported, this assumption has been considered necessary to conduct the optimization study since the panel performance is no longer supposed to be time-dependent.

(2) Flow and temperature fields are two-dimensional. On account of the typical panel aspect ratio of about 18 (width $1.4 \mathrm{~m}$, thickness $0.08 \mathrm{~m}$ ), three-dimensional effects can be expected to be limited to the vicinity of the lateral panel borders with no significant influence on the main flow field.

(3) Air flow is laminar. Calculations of the different $G r$ numbers show that in the range of our simulations, transition to turbulent flow in both the convection channel and in the closed cavity does not arise. In the case of the channel, temperature differences between the two bordering walls (i.e. absorber plate and insulation) are too small to cause turbulence. As for the closed cavity, it can be shown that the heat exchange between absorber plate and glazing is mainly governed by radiation, which leads to a significant reduction of their temperature difference. The calculated $\mathrm{Gr}$ numbers never exceeded the range of validity of the formulae for laminar convection, proposed by either El Sherbiny et al. (1982) or Schinkel and Hoogendorn (1983).
(4) The ideal gas equation of state with constant pressure is valid in order to evaluate density variations in the fluid flow. This assumption implies that density variations can be expressed in terms of temperature only.

(5) Viscous dissipation and compressibility effects are neglected in the energy equation.

(6) Physical properties of air and all materials involved are constant.

\subsection{Convection}

With regard to the general assumptions, the governing equations for the fluid flow inside the dead air space and the convection channel can be written as:

Continuity:

$$
\frac{\partial(\rho u)}{\partial x}+\frac{\partial(\rho v)}{\partial y}=0
$$

Conservation of momentum:

$$
\begin{aligned}
\frac{\partial(\rho u u)}{\partial x}+\frac{\partial(\rho u v)}{\partial y}= & -\frac{\partial p}{\partial x}+\mu \Delta u \\
& +\frac{1}{3} \mu\left(\frac{\partial^{2} u}{\partial x^{2}}+\frac{\partial^{2} v}{\partial x \partial y}\right) \\
\frac{\partial(\rho v u)}{\partial x}+\frac{\partial(\rho v v)}{\partial y}= & -\frac{\partial p}{\partial y}+\left(\rho_{\infty}-\rho\right)+\mu \Delta v \\
& +\frac{1}{3} \mu\left(\frac{\partial^{2} v}{\partial y^{2}}+\frac{\partial^{2} u}{\partial y \partial x}\right)
\end{aligned}
$$

Conservation of energy:

$$
\frac{\partial(\rho u C T)}{\partial x}+\frac{\partial(\rho v C T)}{\partial y}=k \Delta T
$$

Equation of state:

$$
\rho=\frac{p_{\infty}}{r T}
$$

Since large temperature variations and density changes of the fluid can be expected, the Boussinesq approximation has not been applied. Furthermore, eqns (1)-(4) have been used in their dimensional form, since dimensionless numbers such as $\mathrm{Gr}$ require the knowledge of either the temperature or the heat flux on the partition walls bordering the fluid. In our case, however, these characteristics arise from the heat balance inside the panel and cannot be expressed directly.

\subsection{Conduction}

In the solid parts of the panel (glazing, absorber plate and insulation), convection is 
non-existent and the Navier-Stokes equations are confined to the heat equation:

$$
k \Delta T+Q=0
$$

where $Q$ is the internal heat source which corresponds to the part of the solar radiation captured and transformed by the glazing into thermal energy. In assuming an equal distribution of the absorbed incident solar energy over $b_{\mathfrak{g}}, Q$ can be written as:

$$
Q=\frac{G \alpha_{\mathrm{g}}}{b_{\mathrm{g}}}
$$

As far as insulation and absorber plate are concerned, complete opacity to radiation is supposed and the term $Q$ vanishes.

\subsection{Boundary conditions}

The hydrodynamic boundary conditions are the non-slip conditions on all rigid wall surfaces. The inflow boundary conditions of the convection channel have been determined in neglecting the velocity gradients in the direction of the fluid flow and in assuming a given temperature field. The pressure distribution in the entrance region has been calculated according to the Bernoulli equation. Velocity and temperature distribution in the outflow region have been extrapolated from their internal values, whereas the pressure was fixed.

In the case of non-recovery periods, the no-slip boundary conditions have been applied to the closed apertures. In addition, heat transfer in these sections has been neglected.

The thermal boundary conditions are split into internal and external conditions. The latter correspond to the heat exchange with the environment outside the calculation domain:

$$
\begin{gathered}
-k_{\mathrm{g}} \frac{\partial T}{\partial x^{+}}=U_{\mathrm{ext}}\left(T_{\mathrm{ext}}-T\right) ; \\
x=0, \quad 0 \leq y \leq H \\
k_{\mathrm{i}} \frac{\partial T}{\partial x^{-}}=U_{\mathrm{int}}\left(T_{\mathrm{int}}-T\right) ; \\
x=L, \quad b_{\mathrm{in}} \leq y \leq H-b_{\text {out }} \\
-k_{\mathrm{air}} \frac{\partial T}{\partial y^{+}}=U_{\mathrm{b}}\left(T_{\mathrm{ext}}-T\right) ; \\
0 \leq x \leq L, \quad y=0 \\
k_{\mathrm{air}} \frac{\partial T}{\partial y^{-}}=U_{\mathrm{b}}\left(T_{\mathrm{ext}}-T\right) ; \\
0 \leq x \leq L, \quad y=H
\end{gathered}
$$

where $U$ is the global heat-transfer coefficient, including heat losses by radiation. Following the recommendations of the French Building Research Institute (CSTB), $U_{\text {ext }}$ and $U_{\text {int }}$ were fixed at 16.67 and $8.5 \mathrm{~W} / \mathrm{m}^{2} \mathrm{~K}$, respectively. As for $U_{\mathrm{b}}$, it amounts to $6 \mathrm{~W} / \mathrm{m}^{2} \mathrm{~K}$ to account for the additional insulation provided by the wooden frame of the panel.

The internal boundary conditions are located at the different solid-fluid interfaces inside the panel. They are based on the energy balance in assuming that the different surfaces involved behave like grey bodies completely opaque to incident radiation. Furthermore, as the absorptance of the absorber plate is supposed to attain unity, no multiple reflexions occur between glazing and absorber in the solar spectrum. Finally, radiative heat transfer with the upper and lower borders, as well as radiation losses through the inlet and outlet section have been neglected. According to these assumptions, the heat balance of a surface element of the absorber plate can be expressed as follows:

$$
\begin{aligned}
& \left.k_{\mathrm{a}} \frac{\partial T_{j}}{\partial x^{+}}\right|_{x=\left(b_{\mathrm{g}}+b_{\mathrm{d}}\right)} \\
& =\left.\left(k_{\mathrm{air}} \frac{\partial T_{j}}{\partial x^{-}}+\epsilon_{\alpha} \sigma T_{j}^{4}-S\right)\right|_{x=\left(b_{\mathrm{g}}+b_{\mathrm{d}}\right)} \\
& \quad+c_{\alpha} \sum_{m=1}^{M} F_{j-m}\left[\frac{\left(1-\epsilon_{\mathrm{g}}\right)}{\epsilon_{\mathrm{g}}}\right. \\
& \left.\quad \times\left(k_{\mathrm{air}} \frac{\partial T_{m}}{\partial x^{+}}-k_{\mathrm{g}} \frac{\partial T_{m}}{\partial x^{-}}\right)-\sigma T_{m}^{4}\right]\left.\right|_{x=b_{\mathrm{g}}}
\end{aligned}
$$

for $j=1$ to $M$ ( $M$ being the number of nodes in the vertical direction), $S$ expresses the external heat sources and corresponds to the solar radiation transmitted through the glazing and transformed into heat by the absorber:

$$
S=G \tau_{\mathrm{g}} \epsilon_{\alpha}
$$

The different shape factors $F$ are evaluated according to Hottel's rule. The internal boundary conditions of the remaining bordering walls have been treated identically.

\subsection{Reference panel}

The panel dimensions, as well as the thermal and optimal properties of the materials involved, strongly influence the panel performance. In order to ensure that the panel performance remains only a function of channel spacing $b_{c}$, incident solar radiation $G$ and indoor and outdoor temperatures $T_{\text {ext }}$ and $T_{\text {int }}$, the panel 
dimensions and properties have to be fixed. These characteristics have been determined to correspond to those of a typical facade panel encountered in building construction. The reference design characteristics are:

Panel dimensions:

$H=1.5 \mathrm{~m}$

Option 1: $L_{\mathrm{s}}=8 \mathrm{~mm}$,

Option 2: $L_{\mathrm{s}}=b_{\mathrm{g}}+b_{\mathrm{d}}+b_{\mathrm{a}}+b_{\mathrm{c}}+b_{\mathrm{i}}$

Glazing:

$b_{\mathrm{g}}=6 \mathrm{~mm}, k_{\mathrm{g}}=0.81 \mathrm{~W} / \mathrm{m} \mathrm{K}$,

$\tau_{\mathrm{g}}=0.92$ (solar spectrum),

$\alpha_{\mathrm{g}}=0.08$ (solar spectrum),

$\alpha_{\mathrm{g}}=1$ (infrared spectrum)

Dead air space:

$b_{\mathrm{d}}=15 \mathrm{~mm}$

Absorber plate:

$b_{\alpha}=4 \mathrm{~mm}$,

$k_{\alpha}=200 \mathrm{~W} / \mathrm{m} \mathrm{K}$,

$\alpha_{\alpha}=1$ (global spectrum)

Insulation:

Option 1: $b_{\mathrm{i}}=L_{\mathrm{s}}-b_{\mathrm{g}}-b_{\mathrm{d}}-b_{\alpha}-b_{\mathrm{c}}$,

Option 2: $b_{\mathrm{i}}=4 \mathrm{~mm}$

$k_{\mathrm{i}}=0.04 \mathrm{~W} / \mathrm{m} \mathrm{K}, \quad \tau_{\mathrm{i}}=\alpha_{\mathrm{i}}=0.9 \quad$ (infrared spectrum)

The height $b_{\text {in }}$ and $b_{\text {out }}$ of the inlet and outlet sections of the convection channel has been fixed at $20 \mathrm{~mm}$. This value has been found to be a good compromise between efficiency (lower values for $b_{\text {in }}$ and $b_{\text {out }}$ tend to throttle the air flow) and design constraints (inlet and outlet sections are visible on the back of the panel and should thus remain as small as possible).

It should be noted that options 1 and 2 lead to identical panel dimensions when channel spacing equals $15 \mathrm{~mm}$. For lower values of $b_{\mathrm{c}}$, insulation as well as panel are thicker for option 1, whereas for higher values of $b_{\mathrm{c}}$, this order is reversed: $L_{s}, b_{\mathrm{i}}$ (option 2) $>L_{\mathrm{s}}, b_{\mathrm{i}}$ (option 1).

\section{COMPUTATIONAL PROCEDURE}

The conjugate heat-transfer problem arising from the panel configuration has been treated by Patankar's SIMPLER method (1980), which has been successfully applied to similar studies (Ormiston et al., 1986; Ben Yedder and Bilgen, 1991). This method allows the numerical treatment of the pure heat conduction in the solid parts of the panel by introducing an artificial viscosity $\left(10^{15}\right)$, which ensures that a zero veloc- ity prevails throughout this region. The convergence of the numerical procedure has been improved according to suggestions made by Van Doormal and Raithby (1984). Numerical instabilities could be avoided by adjusting the underrelaxation factor.

The linearization of the second term of the right-hand side of eqn (14), necessary to implement the numerical procedure, has been carried out using a Taylor series expansion:

$$
T^{4} \simeq T^{* 4}+4 T^{* 3}\left(T-T^{*}\right)
$$

where $T^{*}$ is the current iterative value of the temperature. The remaining terms in eqn (14) raised to the fourth power were treated explicitly and calculated from their current iterative values.

To cover the whole calculation domain, 40 grid points were displayed in the transverse direction (12 points each in the cavity, the convection channel and the insulation, 2 points in glazing and absorber plate) and 70 points in the vertical one (10 points each in the inlet and outlet section, 50 points between both sections). This mesh (Fig. 3) has been found sufficiently accurate after a preliminary study of grid independence (the calculated difference of the panel output did not exceed $1 \%$ in the case of a fourfold increase in the number of grid points). In

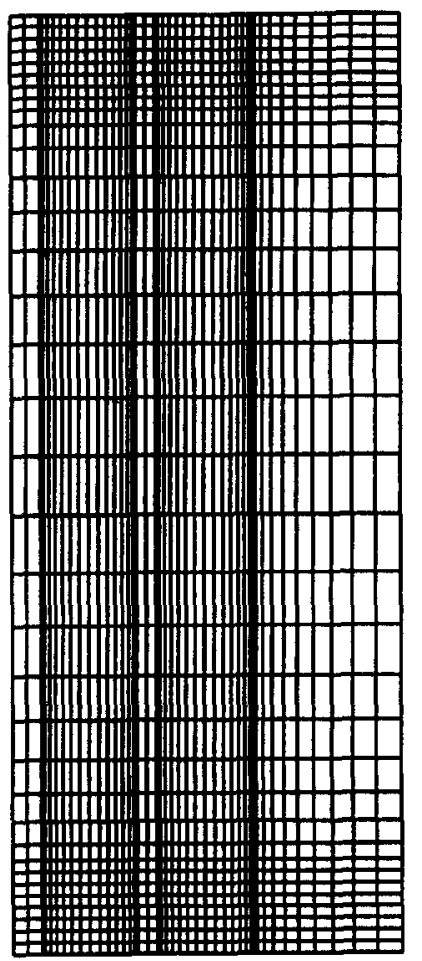

Fig. 3. Example of grid size distribution. 
order to account for the rapid axial and transverse variations of channel velocity and temperature near the solid-fluid interfaces, the grid size has been continuously refined as the boundary approaches. In the solid parts of the panel, where conduction is prevailing, a coarser mesh could be applied.

The numerical model thus derived has been confirmed by a series of experiments conducted with a slightly modified panel version. Good agreement between measurements and simulation with reference to convective heat gains has been found.

\section{NUMERICAL RESULTS}

\subsection{Recovery periods}

The efficiency of the panel in recovering incident solar energy has been expressed according to eqn (1). In order to ensure positive values of efficiency over the whole range of calculations, the outdoor temperature has been set equal to the indoor temperature $\left(20^{\circ} \mathrm{C}\right)$. The panel was submitted to two different intensity solar radiations $\left(100\right.$ and $\left.1000 \mathrm{~W} / \mathrm{m}^{2}\right)$, which represent roughly the lower and upper limit of incident solar energy that can be expected. The channel spacing $b_{\mathrm{c}}$ was varied between 1 and $40 \mathrm{~mm}$. The results of the simulations for the two different options are given in Fig. 4 and show a significant influence of channel spacing on panel efficiency. It can be seen that an increase of incident solar radiation favors encrgy recovery for both options.

5.1.1. Option 1. The dependency of panel efficiency on channel spacing as shown in Fig. 4 agrees well with the theoretical predictions of Aung et al. (1972) concerning natural convection in an asymmetrically heated vertical chan-

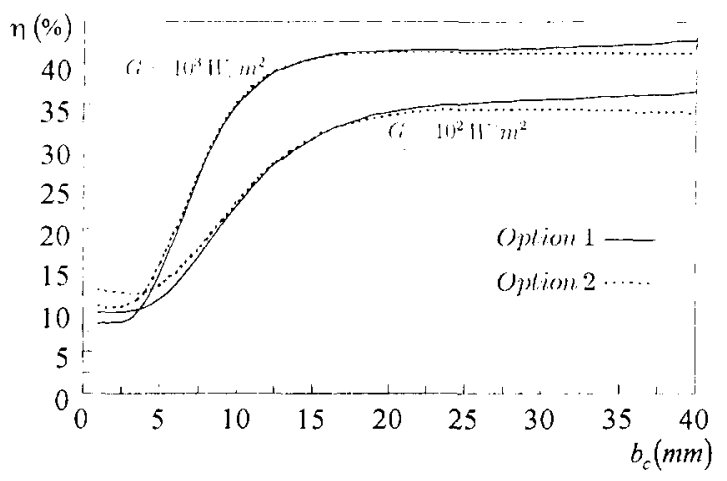

Fig, 4. Panel efficiency as a function of convection channel spacing (recovery periods). nel. When channel spacing and thus $G r$ numbers are low $\left(b_{c}<5 \mathrm{~mm}\right)$, the air flow in the convection channel is fully developed. Consequently, convective heat transport is limited and contributes only marginally to the overall heat gains, which stem mainly from conduction through the insulation. A gradual increase of $b_{\mathrm{c}}$ raises the channel Grashof number, which enhances the convective recovery of incident energy and results in a steep improvement of panel efficiency $\left(5<b_{\mathrm{c}}<15 \mathrm{~mm}\right)$. When the two bordering walls (absorber plate and insulation) are sufficiently far apart to approach the single plate limit $\left(b_{\mathrm{c}}>15 \mathrm{~mm}\right)$, a further increase of channel spacing raises convective gains only slightly. When $b_{\mathrm{c}}$ exceeds $20 \mathrm{~mm}$, the cross-section of the inlet and outlet apertures starts lagging behind the cross-section of the convection channel $\left(b_{\text {in }}, b_{\text {out }}<b_{\mathrm{c}}\right)$. As a consequence, the air flow across the panel is increasingly throttled, which tends to diminish convective recovery. However, despite this impediment, a slight, but continuous, rise of panel efficiency over this range of investigation can be observed. It can be shown that this rise is to be attributed to the improvement of conductive heat gains due to the reduction of $b_{\mathrm{i}}$, which is important enough to outstrip the negative influence of throttling.

5.1.2. Option 2. The results of the simulation are plotted in Fig. 4 and show good agreement between the two options. For low values of $b_{\mathrm{c}}<5 \mathrm{~mm}$, however, higher efficiencies are achicved. Indecd, since $b_{\mathrm{i}}$ is smaller than in option 1, conductive heat gains, which are prevailing in this range, tend to be higher. This advantage, however, declines as the channel spacing increases, until it disappears when $b_{\mathrm{c}}=$ $15 \mathrm{~mm}$, where the panel dimensions of both options are identical. Starting from this point, higher values of $b_{c}$ lead to slightly lower efficiencies than in option 1 : now $b_{\mathrm{i}}$ (option 2 ) > $b_{\mathrm{i}}$ (option 1). When $b_{\mathrm{c}}$ exceeds $20 \mathrm{~mm}$, the growing throttle effect described in the previous section prevents a further rise in panel efficiency. Simulations carried out by increasing $b_{\text {in }}$ and $b_{\text {out }}$ simultaneously with $b_{c}$ showed that the influence of this effect on the panel efficiency is only marginal.

\subsection{Non-recovery periods}

When solar radiation is insufficient to allow energy recovery, inlet and outlet sections have to be closed in order to avoid reverse air circulation in the convection channel. Being cut off 
from the indoor environment, the channel can now be considered as a vertical enclosure.

Numerical simulations have been carried out for two different values of $T_{\text {ext }}$ in assuming a total absence of solar radiation. The results (Fig. 5) compare well with those of a standard building envelope containing an insulation material with properties and dimensions identical to the one used in the panel, e.g. $K \approx 0.7 \mathrm{~W} / \mathrm{m}^{2} \mathrm{~K}$ for a building wall provided with $40 \mathrm{~mm}$ of insulation.

5.2.1. Option 1. The numerical results displayed in Fig. 5 show a continuous rise of the heat-loss coefficient $K$ when the convection channel spacing is increased. Since convective exchanges inside the channel are only marginally affected by changes in $b_{c}$ (see next section) and radiative heat transfer is virtually independent from channel spacing, the steady increase of $K$ is to be ascribed to enhanced conduction through the insulation due to the decrease of $b_{i}$. Heat losses through the panel can thus be more efficiently reduced by choosing low values of $b_{\mathrm{c}}$.

5.2.2. Option 2. Contrary to option 1, a slight, but steady, decline of the panel heat-loss coefficient is taking place when the convection channel spacing is increased. Since the influence of $b_{c}$ on radiative heat transfer is negligible, the decline can only be due to a decrease of convective exchanges inside the channel. This observation agrees with the investigations of Randall et al. (1979) and Schinkel et al. (1983) who point out that a widening of vertical enclosures, submitted to different wall temperatures, tends to lower convective heat transfer slightly. It follows that in the case of option 2 , heat losses

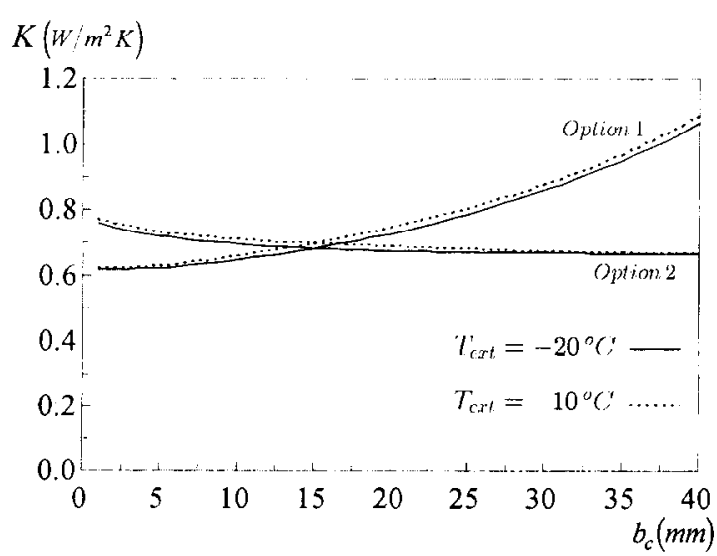

Fig. 5. Panel heat-loss coefficient as function of convection channel spacing (non-recovery periods). through the panel can be minimized by large channel spacing.

\section{CONCLUSION}

Based on the results of our numerical study, the following conclusions can be drawn:

(1) Option 1: no unique optimum for recovery and non-recovery periods could be found. The best panel performance during recovery periods requires a maximum channel spacing, whereas low values of $b_{\mathrm{c}}$ are necessary to minimize heat losses through the panel in non-recovery periods.

(2) Option 2: large channel spacing proved to be the most efficient solution for both recovery and non-recovery periods, although the influence of $b_{\mathrm{c}}$ on heat losses during nonrecovery periods is only small.

It should be noted that during the heating scason in a temperate climate, periods which allow energy recovery are generally outnumbered by non-recovery periods. This observation has no further implications as far as option 2 is concerned, since the most efficient solution (large channel spacing) is identical for both periods. In the case of option 1, however, this solution cannot be advocated since the additional heat gains stemming from a deliberate choice of large channel spacing can be offset by increased heat losses during non-recovery periods. A channel spacing between 15 and $20 \mathrm{~mm}$ is recommended in this case as a reasonable compromise for the reference panel. It should be clear, however, that a different optimum can be expected when the geometrical and optical features of the panel are modified.

\section{NOMENCLATURE}

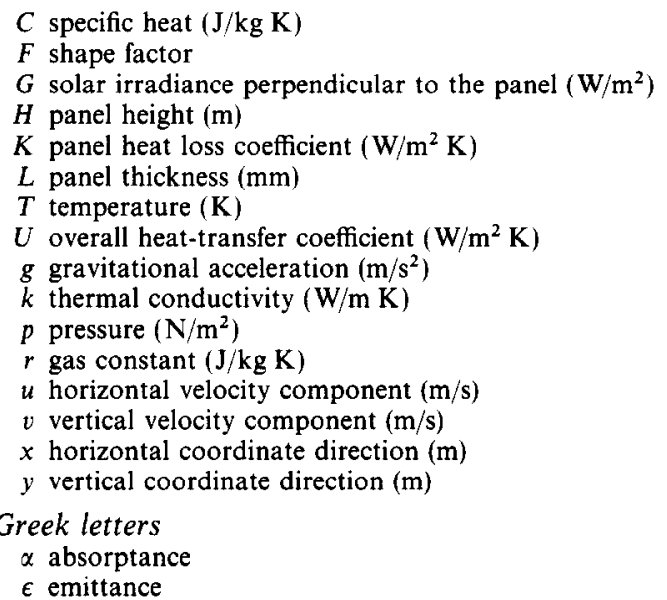




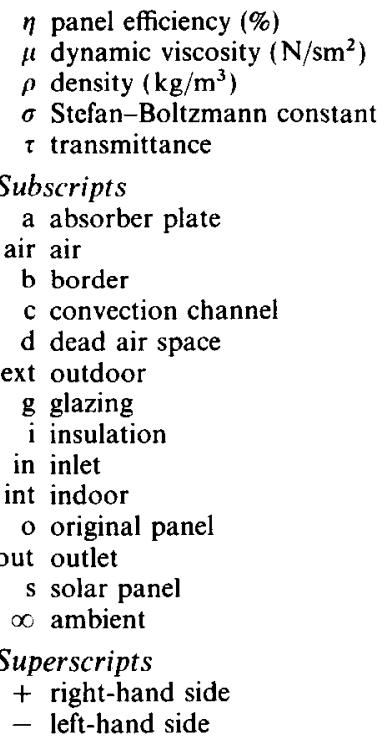

\section{REFERENCES}

Aung W., Fletcher L. S. and Sernas V. (1972) Developing laminar free convection between vertical plates with asymmetric heating. Int. J. Heat Mass Transfer 15, 2293-2308.

Ben Yedder R. and Bilgen E. (1991) Natural convection and conduction in Trombe wall systems. Int. J. Heat Mass Transfer 34, 1237-1248.
Detunq B. and Bilgen E. (1984) Etude expérimentale d'un capteur solaire du type mur Trombe et validation des formules théoriques. Trans. CSME 18, 35--39.

Duffin R. J. and Knowles G. (1985) A simple design method for the Trombe wall. Solar Energy 34, 69-72.

El Sherbiny S. M., Raithby G. D. and Hollands K. G. T. (1982) Heat transfer by natural convection across vertical and inclined air layers. J. Heat Transfer 104, 515-520.

Kenna J. P. (1983a) The multiple layer solar collector. Solar Energy 30, 225-235.

Kenna J. P. (1983b) The thermal trap solar collector. Solar Energy 31, 335-338.

Ormiston S. F., Raithby G. D. and Hollands K. G. T. (1986) Numerical predictions of natural convection in a Trombe wall system. Int. J. Heat Mass Transfer 26, 869-877.

Patankar S. V. (1980) Numerical Heat Transfer and Fluid Flow. Hemisphere, New York.

Randall K. R., Mitchell J. W. and El-Wakil M. M. (1979) Natural convection heat transfer characteristics of flat plate enclosures. J. Heat Transfer 101, 120-125.

Schinkel W. M. M. and Hoogendorn C. J. (1983) Natural convection in collector cavities with an isoflux absorber plate. J. Solar Energy Engng 105, 19-22.

Schinkel W. M. M., Linthorst S. J. M. and Hoogendorn C. J. (1983) The stratification in natural convection in vertical enclosures. J. Heat Transfer 105, 267-272.

Van Doormal J. P. and Raithby G. D. (1984) Enhancements of the SIMPLE method for predicting incomprcssible fluid flows. Numer. Heat Transfer 7, 147-163.

Vaxman M. and Sokolov M. (1985) Analysis of a free flow solar collector. Solar Energy 35, 287290.

Zrikem Z. and Bilgen E. (1987) Theoretical study of a composite Trombe-Michel solar collector system. Solar Energy 39, 409-419. 